\title{
Cultural Identity in Monica Ali's Brick Lane: A Bhabhian Perspective
}

https://doi.org/10.33806/ijaes2000.19.1.4

\author{
Tawfiq Yousef \\ Al-Zaytoonah University, Jordan
}

\begin{abstract}
This paper explores the question of cultural identity in Monica Ali's Brick Lane (2003) through making specific reference to Homi Bhabha's views of hybridity, third space, mimicry and ambivalence. Though Ali's novel has been discussed in light of traditional postcolonialism, it has not been duly scrutinized through a dominantly Bhabhian perspective. Besides making use of Bhabha's theories, this article draws upon the works of some other theorists of cultural identity such as Stuart Hall and Edward Said to highlight its emphasis on a Bhabhian approach. Grounding its discussion in Bhabha's theory of cultural identity, it explores the way/s the major characters in Ali's novel struggle to realize their sense of cultural identity in their own different ways. Specific emphasis is laid on the novel's protagonist Nazneen and the development of her cultural identity.
\end{abstract}

Keywords: Brick Lane, cultural identity, Homi Bhabha, Monica Ali.

\section{Introduction and theoretical background}

In its general meaning, cultural identity can be defined as the feeling of belonging to a certain social or cultural group. According to Oxford Dictionary of Media and Communication, it is "the definition of groups or individuals ... in terms of cultural or subcultural categories (including ethnicity, nationality, language, religion, and gender) (Chandler and Munday 2011: 137).As culture encompasses everything in a society, its effect on the individual's identity is very profound. In "Cultural Identity and Personal Identity", Wren (2002: 213) distinguishes between "personal identity" and "group" or "cultural identity", stating: "The orthodox discourse of social scientists especially that of personality theorists, treats personal identity as an epiphenomenon of group identity". Instead, he treats group identity and cultural identity as identical (232). Basically, personal/individual identity distinguishes a person from everyone else, making him/her unique; cultural identity refers to an individual's sense of belonging to a group, forming a part of their personal identity; so, cultural and personal identity are very similar but still different.

Cultural identities can be divisive and even destructive, but they can also be positive and creative. Culture is an important factor in shaping one's identity; an individual's cultural environment impacts their chosen culture. This particularly applies to immigrants who may find it necessary to change their culture in order to fit into the new culture to which most of the citizens in the country belong. This process creates problems for the individual as $s / h e$ is supposed to make a difficult choice between the two different cultures. It is not 
always necessary to stick to one culture; some people may adjust themselves to more than one culture. Cultural identity is not always fixed or incapable of change or development (Holliday 2010: 165- 177).

Cultural identity has occupied a central place in social sciences and postcolonial studies, particularly postcolonial literature. The varying or divergent views on cultural identity can be attributed to the great changes that have occurred over the past few decades towards the essentialist views of culture that characterized culture studies in the greatest part of the 20th century, giving way to pluralistic and multiple perspectives of culture. The early investigations of cultural identity can be traced back to Erik Erikson (1950) who viewed the process of identity development as one in which personal and group identities are merged into one. Erikson's early identity conception has been echoed in subsequent academic writings about cultural identity (Kim 2007: 240). Given the wide range of different and sometimes conflicting views over the subject, cultural identity is treated in this essay as an inclusive concept that includes social/group/collective and even personal/individual identities. Consequently, both cultural and personal identities are here treated as correlates of the same concept and the various terms associated with cultural identity including group, collective, and social identity are used interchangeably.

\section{Literature review}

Cultural identity, as Kim observes, entails intercultural relations including assimilation, integration, multiculturalism, and separation. Contrary to assimilation which "espouses individualism, a cultural mindset that celebrates individual identity, self-reliance, and personal responsibility, multiculturalism replaces individualistic belief ... with contrary claims of group identity" (Kim: 239). Integration "emphasizes the need to moderate the often tortured reality of identity politics and to search for some kind of reconciliation". Separation leads to "us-against them" posturing, advocating a maximum intergroup distance and, in some cases, resorting to self-glorification and denigration and even violence and terror (240). Yasmin Hussain notes that "culture is not genetically inherited but is instilled by upbringing within a given cultural context" (Hussain 2016: 3).

The theme of identity explored in Brick Lane is not restricted to personal/individual but also embraces collective/group/social or cultural identity of Bangladeshis in London. The quest for identity is presented as a means of expressing self-identity and ultimately cultural identity. This brings the characters into a questioning confrontation with their own heritage and the values of the culture in which they find themselves. The quest for identity through space and time and the constraints of cultural heritage and patriarchy are basic themes in Brick Lane as indeed in most diaspora fiction.

In contrast with Edward Said's view of fixed binary oppositions particularly of the social relations between the imperial center and the colonial periphery (Said 1978), recent scholarship on cultural identity has tended to emphasize a more flexible relationship between the colonizer and the colonized. This attitude is clearly reflected in the works of such cultural theorists as Stuart 
Hall, Akhil Gupta, James Ferguson, and more importantly, Homi Bahbaha. In "Cultural Identity and Diaspora," Hall (1994: 224-226) describes two different aspects of cultural identity: firstly, cultural identity as seen from the communal perspective, where individuals locate themselves in a shared culture, and secondly, as seen from the personal perspective, where individuals differentiate themselves from others around them. Cultural identity is affected by the location and the community we live in, but it is not completely determined by them. Hall conceives of cultural identity as an ongoing product of history and culture, rather than a finished product. Maintaining that identity is not as transparent or unproblematic as it is generally thought, Hall observes: "Perhaps instead of thinking of identity as an already accomplished fact, which the new cultural practices then represent, we should think, instead, of identity as a 'production' which is never complete, always in process, and always constituted within, not outside, representation" (Hall 1994: 222). He further explains that "cultural identity is a matter of "becoming" as well as of "being"; it belongs to the future as well as to the past" (Hall 1994: 225).

Criticizing the traditional notion of cultural wholes and fixed identities, Gupta and Ferguson (1992: 6-7) argue that it is inaccurate to tie specific cultural formations to a certain people inhabiting a particular place. They maintain that the tendency to take for granted that each country embodies its own distinctive culture and society is based upon a seemingly unproblematic division of space and on the assumption that they occupy naturally and inherently discontinuous or fragmented spaces resulting in the division into diverse national societies, each rooted in its proper place. Postcolonial discourse, they point out, stresses the notion of "deterritorialization"; and so, any attempt to map the world as a group of discontinuous cultural regions or homelands is challenged by a blurring of familiar lines between supposedly distinct identities such as the centre and periphery, the colony and metropole, the here and there (Gupta and Ferguson 1992 :10). They conclude that in a globalized world, traditional cultural fixities and certainties become vulnerable and the notion of the cultural distinctiveness of people is eroded (9), a view that raises the question of hybridity.

As Bhabha has exerted a tremendous influence on recent cultural theory by his introduction of new key concepts such as hybridity, third space, ambivalence, and liminality, his views will receive substantial attention in this article and will form the springboard for the ensuing discussion. Drawing upon Jacques Derrida's strategies with a view to deconstructing Said's theory of culture, Bhabha poses his own theory which takes a different view of both the colonial "subject" and the colonial nation-state. In his introduction to The Location of Culture, Bhabha (1994) sheds light upon the "liminal" negotiation of cultural identity across differences of race, class, gender, and cultural traditions. $\mathrm{He}$ argues that cultural identities cannot be ascribed to pre-given, ahistorical cultural traits that define the conventions of ethnicity nor can "colonizer" and "colonized" be viewed as separate entities that define themselves independently. Instead, Bhabha suggests that the negotiation of cultural identity involves the 
continual exchange of cultural performances that in turn produce a mutual recognition of cultural difference. This "liminal" space is a "hybrid" site that witnesses the production of cultural meaning: "The representation of difference must not be hastily read as the reflection of pre-given ethnic or cultural traits set in the fixed tablet of tradition. The social articulation of difference, from the minority perspective, is a complex, on-going negotiation that seeks to authorize cultural hybridities that emerge in moments of historical transformation" (Bhabha 1994: 2).

Bhabha uses the concept liminality to designate a space or state which is situated in-between usually clearly defined spaces, periods or identities. Liminal space is the meeting-point between convergent positions, but it defies boundaries and erases the differences upon which regulatory frameworks depend. In postcolonial theory, the concept has been employed to show the existence of a cultural space in-between the colonized and the colonizer. In these liminal spaces of transcultural exchange, the colonized subject may find resources and strategies for identity-transformation that upset the fixed polarities of colonial discourse. Bhabha (1994) critiques what he labels "essentialist" views of cultural identity, those that try to define the Third World nations (previously the colonized countries) by means of a supposedly historicallycontinuous and holistic narratives whose primary aim is to define and perpetuate the subordinateness of those countries. Cultural identity (nationhood), he argues, is a constructed narrative that arises from the hybrid interaction of contending cultural and national forces. For Bhabha, the notion of cultural liminality, should replace the essentialist polarity between a nation and other nations (1994:148). Interstitiality, hybridity, liminality, Bhabha maintains, should undo any facile binary oppositions (1994:142).

Rather than focusing on polarities, Bhabha urges for a greater concentration on border situations as the spaces where identities are performed and contested (1994: 12).Third space is a transcendent concept that is constantly expanding to include an "other", thus enabling the contestation and renegotiation of boundaries and cultural identities. For Bhabha, as Jonathan Rutherford notes, "all forms of culture are continually in a process of hybridity that displaces the histories that constitute it, and sets up new structures of authority, new political initiative. The process of cultural hybridity gives rise to something different, something new and unrecognizable, a new area of negotiation of meaning and representation" (Bhabha 1994: 211). Third space theory challenges essentialist models of identity by asserting the uniqueness of each person or context as a "hybrid" of their unique set of identity factors. It represents the fusion of the first space and the second space into a networked place that can be inhabited by multiple factors engaged with one another. Refusing Said's and Fanon's traditional notions of binary oppositions, Bhabha argues that hybridity is what is "new, neither the one nor the other" (1994:25). Consequently, none of the contesting cultures is pure or genuine.

Defining mimicry, Bhabha states: "Colonial mimicry is the desire for a reformed, recognizable other, as a subject of a difference that is almost the 
same, but not quite. Which is to say, that the discourse of mimicry is constructed around an ambivalence" (1994: 86; italics in the original).Mimicry arises from the colonized individuals' imitations of the colonizers accompanied by a feeling of inferiority. It is "a sign of a double articulation; a strategy which appropriates the Other as it visualizes power" (Bhabha 1994: 86). Mimicry gives the colonial subject a partial presence, as if the "colonial" is dependent for its representation upon the ambivalence inherent in mimicry. Bhabha argues that "cultural production is always most productive where it is most ambivalent" and sees mimicry as a double vision which, in disclosing the ambivalence of colonial discourse, also disrupts its authority (1994: 86). He maintains that this ambivalence presents a split in the identity of the colonized other and allows for human beings who are a hybrid of their own cultural identity and the colonizer's cultural identity. Accordingly, the colonial presence remains ambivalent, split between its appearance as original and authoritative and its articulation as repetition and difference.

\section{Discussion}

Monica Ali's Brick Lane(2003)has been studied from various perspectives: feminism, postcolonialism, race, ethnicity, identity, etc. Nevertheless, none of these studies has dealt with it primarily from the perspective of cultural identity as reflected in Homi Bhabha's theories. This paper takes its cue from previous postcolonial studies dealing with the issue of identity with a view to elaborating the theme of cultural identity as represented in Ali's novel while contextualizing it within Bhabha's theories of cultural identity. It also builds its discussion on the view of some cultural theorists who argue that the link between people and place is not naturally given but constructed and reconstructed from the multiplicity of social relations and in their interaction with one another in everyday discourses as well as in extraordinary experiences such as displacement, emigration and exile. The paper espouses the current view that the essentialist understanding of the relationship between people, identity, and place as naturally and unchangingly linked has lost some ground following the advent of the more recent postcolonial theoretical debate about this issue.

Brick Lane can be read as an attempt to address the problematics of identity, displacement, hybridity, assimilation, integration, separation, marginalization, alienation and other concomitant concepts through its use of the fictional story of some Bengali immigrants living in London and exposed to a markedly different culture, showing how these factors affect the cultural identity of the characters. The ambivalent feelings the characters experience reflect an ambiguity that blurs the distinctions between the here and there, the homeland and the host country. This state of in-betweenness challenges the traditional understanding of what is authentic and what is peripheral. In the novel, social, political and cultural spaces overlap with geographical areas, thus problematizing the issue of cultural identity. The novel shows how cultural identity affects the way immigrants move and organize themselves in the host 
country creating a minority community within the dominant culture. At the same time, it presents a combination of different nationalities and cultures resulting in a free flow of ideas and cultural images. The characters' reflections upon their culture lead to a mapping of space in a way that runs counter to the traditional representations of national space and identity. The novel's Bengali community forms social groups and associations such as the Bengal Tigers that try to respond to the needs of the Bengalis whether in the home or in the host country and to counter a fictional rival group from the white community, the Lion Hearts (Ali 2003:240-241). The focus moves beyond the boundaries of a nation-state comprising one culture to a mixture of several nationalities and cultures producing a multicultural community as well as a free third space amenable to a new social and individual culture formation.

Brick Lane depicts the life of a Bangladeshi family that emigrated from Bangladesh (a former British colony) to live in London, with special concentration on the last twenty years or so of the 20th century and the early years of the 21st century. In London, the novel's protagonist Nazneenis caught within two different cultural milieus with obvious negative social, emotional and health consequences. Nazneen's life is a story of self-discovery and selfrealization: "When she had come [to England] she had learned first about loneliness, then about privacy, and finally she learned a new kind of community" (Ali: 182). Nazneen's journey of exploration and discovery has provided her with a spiritual awakening and the ability to survive on her own. She is living neither in her original Bengali world nor in the Western world but in some middle or in-between world. In Bhabhian terms, she does not merely try to form a hybrid identity but to forge a new one based on a fusion of two opposing cultures. Hybridity opens up a space where the construction of a new cultural identity is feasible, an identity that belongs neither to the Colonizer (the host culture) nor to the Other (the Bengali culture) with the presence of metropolitan culture and authority remaining ambivalent or no longer immediately visible. Consequently, Nazneen's new identity is not given but something constructed and contingent. As Bhabha's views are based on the power relations between the dominating and the dominated countries/powers during colonial times, so can characters' relations in postcolonial literature be viewed in a parallel manner. In Brick Lane we witness a semblance of the colonizer-colonized relationship envisaged in Bhabha's The Location of Culture. Ali focuses on power relations emerging from the identity construction of her major characters. The focus in the novel is not on the dominating influence of the colonizer (British) on the dominated (Bengali) but on exploring an in-between area which brings together the two opposing sides without infringing upon their potential powers.

The hybridity setting of the novel creates a good environment for Nazneen to develop a richer and more responsive identity that can respond to both her old and new cultural background. Unlike her husband, Nazneen understands the value of collaboration, assimilation and integration. Following Kim's aforementioned argument about assimilation and engagement, assimilation 
empowers Nazneen to assert her own individual identity and self-reliance while engagement makes her seek mutual accommodation and balance with their ambivalence and contradiction. As Sterrett (2015:657) observes: "it is unlikely hybridity and identity development would occur without authentic engagement". Ali seems to be acknowledging the third space encounter and its effect on her protagonist as a transformative power in her life and cultural education. As she encounters the narratives of other people from her society, Nazneen enters that liminal third space where she realizes there is another way of viewing the world and her identity. In terms of Bhabha's theory, this is a space where new cultural values and norms can occur and can be learned, "a place where we construct our identities in relation to varied and often contradictory systems of meaning" (Bhabha 1994: 38). Thus, hybridity is as much about transcending boundaries through creating a new identity as it is about producing new spaces through pursuing new areas of cultural knowledge. Within the new third space created as a result of the cultural encounter between West and East cultures, different ideologies co-exist and continue without much fragmentation or distinct divisions (Bhabha 1994 "Introduction"). Throughout the novel, we witness Nazneen moving between two different cultures, creating a new space which does not belong to either one of the two worlds.

At the beginning, Nazneen has to endure a claustrophobic, static existence. Chanu is her only connection to the outside world. Nazneen's grasp of English is very poor and her husband does not encourage her to learn the language; "where's the need anyway?" (Ali: 37 ), he tells her. For the time being, the TV is Nazneen's only window on the outside world. The most important lesson she learns through this avenue is the desire to be independent and in harmony with her surroundings, just like the ice-skater she watches on the screen, who can move freely while in control of her elegant body and in harmony with her partner (Ali:41). Nazneen struggles to adapt to London life; she cannot separate her personal life from the outside world. She has to make sense of her surroundings as a means of understanding, communicating with and adapting to the new community. She is torn between the place of settlement and her home, the public and the domestic spaces respectively. Sewing provides Nazneen with an income and the opportunity to move outside her restrictive domestic space. It is her way of creating a true identity for herself. Having spent 18 years of her life in a village in Bangladesh before moving to London to live within a Bengali community, Nazneen is initially portrayed as a typical Muslim woman who is oppressed under traditional patriarchy. Her husband is chosen by her father and she has to obey her husband's demands without any opposition. However, she gradually discovers herself and decides to divorce Chanu, to set up her own business and to forge her new identity.

The overlapping of identities characteristic of the diasporic experience as treated in Brick Lane leads to cultural hybridity. Nazneen's identity cannot be 
categorized as being exclusively British or entirely Bengali. Relying on a negotiation of difference, hybridity brings into contrast the narratives of home and host culture. Hybridity includes a sense of contentment with the original culture and a desire to assimilate elements from the new culture, leading to the displacement of old values and the adapting to the new surroundings. Unlike Chanu, Nazneen is prepared to incorporate Western elements into her identity while keeping many elements of her cultural heritage such as her prayers and her Qur'an recitations. That is why her life can be seen as a process of cultural education. According to Bhabha, hybridization is not restricted to the sum of the differing elements but emerges through a process of opening a "third space" where elements of divergent origins meet, producing a mutual transformation (Bhabha 1990: 211). Nazneen tries to negotiate her own space between her original culture and the dominant culture. As Hussain (2016:11) explains: "The third space is an open expansive space encouraging the assimilation of contrary signs and metanarratives which obviously remain a necessary precondition for the articulation of cultural differences and the inscription of cultural hybridity". For Bhabha, the third space is a liminal space where identity is constructed in relation to varied and often contradictory systems of meaning. Accordingly, cultures are neither unitary nor dualistic, the I and the Other. Following the encounter between two opposing cultures, a new meaning/interpretation emerges which is neither the one nor the other (Bhabha 1994: 53).

In her representation of Nazneen's cultural development, Ali seems to be doing something akin to Bhabha's philosophical theories. As Bhabha rejects the attempt to fix and control indigenous cultures and the illusion of cultural isolation or purity, arguing instead that the various factors of race, ethnicity, community and nationality converge and intersect, Ali seems to be suggesting that her heroine's identity is the outcome of a gradual adaptation to a new culture without completely foregoing her indigenous culture, thus destabilizing the notion of stable, fixed identities. By embedding Brick Lane within the context of hybridity, we can see how Ali, like Bhabha, is opposed to any holistic or essentialistic notion of culture based on the idea of pure exclusion and inclusion. Rejecting traditional notions of identity, Bhabha observes: "The time for 'assimilating' minorities to holistic and organic notions has dramatically passed. The very language of cultural community needs to be rethought from a postcolonial perspective" (Bhabha 1994: 175). Bhabha emphasizes what he describes as culture's "in-between" spaces between individuals and cultures which are not stable but continue forming identities in an on-going process. Similarly, Ali's novel seems to be challenging the traditional notion that an individual's identity is determined by some basic inherent factors and suggests instead that individuals can be defined through a mixture of cultural influences which determine a character's identity or what Bhabha would call "cultural hybridity". Consequently, both writer and theorist seem to propose that cultural identity is not an imitation of a colonial culture but a multicultural and a cosmopolitan one that rejects treating cultural identity in terms of polar opposites with separate and unequal entities. It is in what 
Bhabha calls third space that the novel's protagonist negotiates and articulates her cultural identity, creating a new identity.

In Brick Lane, cultural hybridity is processed as a problematic concept where identity formation is developed on the premise of the malleable boundaries between the "I" and the "Other". The hybrid identity developed as a result of crossing such boundaries is decisive and strong-willed as it enables characters to adapt to the host community. The importance of the third space is that it provides a new understanding of cultural identity whereby "the meanings and symbols of culture have no primordial unity fixity; that even the same signs can be appropriated, translated, rehistoricized, and read anew" (Bhabha 1994:37). The overlapping of identity elements forms a playground for potential tension and conflict that can lead to the creation of the new hybrid (cultural) identity. Thus, hybridity becomes an effective way for the characters to assimilate themselves into the British culture; failing to do that would lead to alienation, isolation and separation. Consequently, identities cannot be strictly reduced to fixed categories, for there is much space for cultural values overlapping. Hall (1998:5) maintains: "We are all ethnically located and our ethnic identities are crucial to our subjective sense of who we are". Hybridity gives a larger scope for identities and identity formation even though the essentialist view which sees identity as entrenched in notions of territorial boundaries still persists. By its fusion of the local with the multifaceted formations of cultural identity, hybridity expands the scope of both personal and cultural identity producing more resilient localized identities of a more pluralistic and egalitarian type. All this comes about "largely through the intervention of the 'third space' and new diasporic communities" (Hussain 2016:12).

Cultures create boundaries that run along differences in ethnicity, language and religion. As newcomers, Nazneen and Chanu are at an in-between or third space in the sense that their identity is torn between their original culture and the new culture they are exposed to for the first time. They are in an ambiguous area where statements about their identity clash with other views. In the third space, differing cultures collide, allowing new concepts of cultural identity to potentially take shape. However, Nazneen and Chanu respond differently to the new cultural environment. Though Nazneen reacts interactively to her new surroundings, Chanu fails to negotiate a positive connection between his traditional culture and Western culture and consequently fails to carve a space for himself in the majority culture. Fernandez (2009:44) points out that Brick Lane, instead of asserting a space of its own in a society it is entitle to, "attempts to (re)define that space as a hybrid location that is an inherent part of British contemporary society". Fernandez (2008:144).adds that this new space is problematic because "it is characterised by ambivalence and an ongoing process of juggling notions of belonging and exclusion" 
Of all the characters in the novel, only Chanu is a misfit who cherishes the desire of return and abhors the idea of staying in Britain or integrating with the London community. Responding to Dr. Azad's fears about the effect of the host culture on Bengali children, Chanu affirms: "I don't plan to risk these things happening to my children. We will go back before they get spoiled" (Ali:.32). Whereas Nazneen eventually tries to melt into the surrounding culture, Chanu self-consciously attaches himself to his place of origin and remains adamant about his perception of the "Going Home Syndrome" (Ali: 32). Chanu's loyalty to his country of origin calls into question his loyalty to the host country. Despite his keenness on getting promoted, he frequently expresses his detestation of Western culture, reiterating "the clash between Western values and our own" (Ali: 113).

Chanu's racist discourse leads to his isolation, alienation and separation from the community. Bridled by a bigoted and a racist mindset, he is unwilling to allow Nazneen to travel alone, to learn English and even to have communication with the local community. Chanu is also frightened that his children will be exposed to "Western corruptions", and so he determines to move back to Bangladesh with his family to avoid this ending. His main aim is to return his family to Bangladesh and to give them a more traditional upbringing, though his family strongly resists all his attempts. A strong opponent to Western culture, Chanu continuously vents his anger out at the way Bangladeshis, Muslims and Muslim heritage are treated in the community. Throughout the novel, Chanu questions his identity and is torn between Western culture and Bengali-Islamic culture. He wishes to maintain his supposedly Western education, while simultaneously remaining connected to his Bangladeshi identity and heritage. This proves problematic, for he is ultimately compelled to choose between his "London self" and his "Bengali-Muslim self." His single-mindedness leads him to a difficult and limited choice: to go home. Chanu's story, contrary to Nazneen's story, demonstrates how living between two cultures can lead to marginalization and ultimately to a sense of disconnection and alienation from one culture and an extreme sense of belonging to another one.

By contrast, Nazneen manages to find a place in the new culture and finally assimilates and integrates into its values and cultural norms. This outcome leads us to think about the marginalized position of contemporary immigrants in terms of Bhabha's conception of third space, the in-between space by whose exploration "we may elude the politics of polarity and emerge as the others of our selves" (Bhabha 1994: 39). Nazneen has changed in terms of her knowledge of new norms, of other people and cultures and of a new way to view the world. This is her first step to being a responsive and collaborative participant in the new culture. She has learned that there is always another way. Throughout her third space experience, she learns how to normally accept differences between social and cultural groups and to develop and embrace a new sense of community and identity. She now knows how to socialize in the new values and traditions of her society and how to negotiate her identity on her 
own terms without solely belonging to any of the parties involved in the cultural encounter. Her new identity is the outcome of the fusion of her traditional culture with the new culture she has known and experienced during her stay in Britain. At the end of the novel, we see her standing at the cross-roads between her previous way of structuring her identity and the new way:

A woman swooped by one leg. No sequins, nor short skirt. She wore jeans. She raced on, on two legs.....

She said, 'But you can't skate in a sari.'

.... 'This is England,' she said. 'You can do whatever you like".

(Ali: 492)

Brick Lane depicts the plurality, the diversity and the multicultural way of life in which ethnically diverse people live. It challenges the previous notion of a homogenous society, thus problematizing contemporary British social space by revealing the diversity and multiplicity of British way of life. The spaces where the characters are located are depicted as being in a continuous process of (trans)formation and change and their identities are represented as being fluid and flexible. Nazneen, Razia, and Shahana inhabit an area that is changing from a monoethnic to a multiethnic community and reveal different levels of integrating into it. As these characters keep producing and reproducing themselves through transformation and difference, their identities and the spaces they inhabit are not fixed but adaptable and heterogeneous.

Though Nazneen and Chanu may have a choice in whether to stay or depart, their daughters seem not to have much of a choice. As Hussain (2016:5) notes: "A first generation immigrant may have a choice as to whether or not to become part of a diaspora. There is less of a choice for daughters or sons when the parents have clung to their cultural roots". The novel includes characters that can be defined in terms of longing for homeland (Chanu), or belonging to more than one place (Nazneen, Razia, Mrs Azad), or cross-fertilization of two cultures (Shana, Bibi). Chanu represents a typical diasporic figure who experiences belonging to an identity rooted in his country of origin (Bangladesh). The dream of returning to his home country (Going Home Syndrome) provides an essential component of his diasporic cultural identity.

In Brick Lane there is an obvious conflict arising from the generation gap between first- and second-generation Bangladeshi immigrants and their Londonborn children. This is clearly manifested in the conflict between Chanu and his eldest daughter Shahana. Shahana just wants to socialize and be like everyone else in her community even though this is in sharp conflict with her father's desire to foster in her an appreciation of her cultural heritage. Hall (1995: 4) maintains that "identities are never unified and, in late modern times, increasingly fragmented and fractured; never singular but multiply constructed across different, often intersecting and antagonistic, discourses, practices and positions". Shahana finds herself living within a social context that conflicts with that which she shares with her parents at home. The result of that conflict is 
her further removal from both her parents' Bangladeshi culture and the indigenous Western culture she has been born in. Brick Lane addresses multiple levels of contradiction and conflict around issues of collective and individual identity. We notice Shahana's movement between cultures as she tries to redefine her personal as well as her cultural identity. Her choice of clothes becomes a physical manifestation of the in-between, the unstable and fragmented nature of her identity. The depiction of Shahana's shifts between jeans and shalwarkameez symbolizes the conflict between her traditional values at home and the public values of the London society: "She wanted to wear jeans. She hated her Kameez and spoiled her entire wardrobe by pouring paint on them" (Ali: 80).

The identity struggles of the children are in sharp contrast with those of their parents. The children are trying to find their own space by drawing on the culture they have been brought up in and by appropriating or rejecting the culture of their parents. Shahana's and Bibi's as well as Razia's children's identities are primarily constructed according to British cultural norms without having any strong sense of belonging to Bangladesh. Consequently, their integration into the British culture does not involve a constant process of oscillation between two cultures as noticeable in the case of Nazneen, Mrs. Azad and Razia. Razia embraces the possibility of her London-born children adapting to English culture and views herself "liv[ing] like the English" (Ali: 358). Mrs. Azad believes that as they live in a Western society, Bengali children should be Westernized. Addressing Chanu, she says: "Fact: we live in a Western society. Fact: our children will act more and more like Westerners. Fact: that's no bad thing" (Ali: 113).

Bengali characters act in different ways regarding their identity formation. Chanu isolates his wife as well as himself not only from the surrounding British society but also from the local Asian community. Considering himself superior to whom he sees as the illiterate Bengali immigrants, Chanu insists on drawing solid boundaries between himself and the other members of the Bengali community, establishing connections only with well-off Bangladeshis such as Dr. Azad (Ali:34). His isolation from his Bengali community and London society has deepened and his grandiose plans and bragging speeches about himself and his home culture begin to deteriorate. Having failed to get promoted, he is driven into feelings of alienation, disillusionment and hopelessness and begins to translate his "Going Home Syndrome" into action. Curbed by his fanaticism, Karim, like Chanu, does not find a space in this liberal world and will soon travel on his jihadi mission to join his "brothers" in Bosnia and Chechnya (Ali:243). In contrast with Chanu's antagonistic talk about clash of civilizations and cultures and Karim's fanatic discourse, Mrs. Azad calls for assimilation and integration of the immigrant Bengali community into local culture and considers herself and her daughter as being Westernized. Razia dresses and acts in a Western lifestyle and encourages Nazneen to become economically independent and to pursue her English language learning. 
On her journey to identity formation, Nazneenis guided by various factors coming from her own culture as well as British culture. Stimulated by the example of her sister's refusal of an arranged marriage, Nazneen takes up her personal responsibility, fighting for her right to a space in this world. Her friendship with Razia and Mrs Azad has encouraged her to become free and self-reliant. Razia, a first-generation Bengali immigrant whose difficult circumstances have prompted her to become a Westernized woman with a job, encourages Nazneen to go to college to learn English (a basic medium of communication), to earn money and become independent (Ali: 114). Even Nazneen's elder daughter Shahana provides a role model of feminine independence through her bold response to her father's undesirable, restrictive instructions.

Nazneen's education derives also from her husband Chanu and her lover Karim. Chanu's disrespect for his young wife leads her to look for the outside world where she can get some work or meet other people and ultimately achieves a sense of self-realization. Chanu's deteriorating financial situation enables Nazneen to take up a job and eventually to meet Karim, her new-found lover. Karim is perhaps the strongest stimulant of Nazneen's transformation to independence and a new cultural identity. A second-generation immigrant in London, Karim helps Nazneen discover herself, become integrated into society and finally stand up for herself. Karim's understanding makes Nazneen feel respected and loved. Karim makes Nazneen realize the need for a radical change in her life and for a final transformation in her cultural identity. However, Nazneen chooses neither to go back with Chanu nor to marry Karim. Instead, she becomes an independent and free woman who decides to stay in London and take care of herself as well as her two daughters and to follow her own way of life. Now, she can play freely in the snow, a symbolic action that suggests her ability to forge a third space that empowers her to act freely and independently in her society as a cultural hybrid.

Characters in this novel attempt to trace their roots back in their home county or endeavour to see their belonging to a host community in order to negotiate their identity status. The space where the negotiating of identity takes place may extend from a home setting to a workplace setting, from the home country to the host country, or even to Europe or any other place. The quest is primarily for personal or group identity but without emphasizing the role of race or ethnicity (excepting Chanu). In Bhabhian terms: "culture is less about expressing a pre-given identity (whether the source is national culture or 'ethnic' culture) and more about the activity of negotiating, regulating and authorising competing, often conflicting demands for collective self-representation" (quoted in Fernandez 2009:157). Brick Lane stresses hybridity and celebrates the third zone where social spaces are constantly being negotiated and inscribed with variable and flexible meanings. As a result, the claims to innate originality or purity of cultures are vulnerable, for culture has no fixity and can be appropriated, negotiated, and read anew. 
In Brick Lane, we notice the protagonist's final integration into contemporary British society. As a non-typical postcolonial text, Brick Lane subverts the old opposition between Western and Eastern values towards a more open and fulfilling multiculturalist society. Ultimately, Nazneen decides to stay in England even against Chanu's will. In the course of the novel, Nazneen has developed from an introverted and submissive personality into an independent and self-reliant character that can ice-skate and even dance and sing freely (Ali: 489). Ali Westernizes her protagonist's lifestyle and experiences and empowers her to take charge of her destiny. At the end of the novel, we see Nazneen iceskating, wearing a sari, and without inhibition. Symbolically speaking, the skating-rink represents the new space to which Nazneen can move while maintaining her first space represented by her sari (widely regarded as a symbol of the cultures of the Indian subcontinent). By fusing these two spaces, Nazneen has been able to move to a third space where she can find her hybrid identity that is an amalgamation of the two spaces without being caught in a constraining polarity between the two spaces. From a postmodern Bhabhian perspective, Nazneen's journey begins from submissiveness (the space of the colonized) to independence (the space of the colonizer) leading ultimately to her fusion and transcendence of the two worlds (the space of the hybrid) where she can achieve her self-realization.

\section{Conclusion}

Brick Lane celebrates integration between ethnically diverse groups. Its representation of cultural identity contributes to acknowledging the existence of other identities in British society while concomitantly admitting the naiveté of any view that ignores the role of power relations even in a liberal and democratic society such as the British society. The novel depicts cultural identity in Britain as being heterogeneous and in an ongoing process of redefinition. Characters such as Nazneen, Razia and Mrs. Azad inhabit a hybrid space from which emerges a new cultural identity that is multicultural and multilocational. Third space allows them to meet on new national and geographical spaces that include the values of the home and those of the host culture. As Mrs. Azad beautifully puts it: "When I'm in Bangladesh I put on a sari and cover my head and all that. But here I go out to work. I work with white girls and I'm just one of them. If I want to come home and eat curry, that's my business" (Ali: 114). British-born children and even their mothers are under pressure to reform and redefine their identity status in light of this intercultural fusion. The novel contributes to a hybrid view of British society and seems to advocate a new conception of identity based not on the postcolonial notions of polarity or of multiculturalism and multiple identities but on a fusion of identity set against the background of contrasting cultures. The new identity and the social spaces created are based on the notions of hybridity and the third space associated particularly with Homi Bhabha for whom hybridity is something 
productive and a means of questioning culture as a stable entity that confers a homogeneous identity.

Tawfiq Yousef $(\mathrm{PhD})$

Al-Zaytoonah University

Amman-Jordan

Email:drtawfiq@yahoo.com

\section{References}

Bhabha, Homi. (1990). 'The Third Space. Interview with Homi Bhabha'. In Jonathan Rutherford (ed.), Identity: Community, Culture, Difference, 207221.London: Lawrence and Wishart.

Bhabha, Homi. (1994). The Location of Culture. London and New York: Rutledge.

Chattopadhyay, Sagarika and Jaya Shrivastava. (2012). 'Transitional identities and the unhomed space in Monica Ali's Brick Lane and Tishani Doshi's The pleasure seekers'. Asiatic, 6 (1):111- 124.

Chandler, D. and R. Munday. (2011). Oxford Dictionary of Media and Communication. Oxford: Oxford University Press.

D'Arcy, Rebecca Mary. (2015). 'Identity, material culture and thing theory in two British migrant novels'. Postcolonial Text, 10 (2): 1-12.

Erikson, Erik. (1950). Childhood and Society. New York: W. W. Norton.

Fernandez, Irene Pérez. (2009). 'Representing third spaces, fluid identities and contested spaces in contemporary British literature'. Journal of the Spanish Association of Anglo-American Studies, 31(2): 143-160.

Gupta, Akhil \& James Ferguson. (1992). 'Beyond culture: Space, identity, and the politics of Difference'. Cultural Anthropology, (71): 6-23.

Hall, Stuart. (1998). 'Cultural identity and diaspora'. In Jonathan Rutherford (ed.), Identity: Community, Culture, Difference, 222-237. London: Lawrence and Wishart.

Hall, Stuart. (1995). 'Interview with Roger Bromley'. In Jessica Munns and Gita Rajan (eds.). A Cultural Studies Reader: History, Theory, Practice, 659-673. London: Longman.

Holliday, Adrian. (2010). 'Complexity in cultural identity'. Language and Intercultural Communication, 10 (2): 165-177.

Hussain, Yasmin. (2016). Writing Diaspora: South Asian women, Culture and Ethnicity. New York: Routledge. 
Kim, Young Yun. (2007). 'Ideology, identity, and intercultural communication: An analysis of differing academic conceptions of cultural identity'. Journal of Intercultural Communication Research,36 (3):237253.

Majed, Hassan. (2012). Islam and Muslim identities in four contemporary British novels. Unpublished Ph.D. thesis, University of Sunderland, Scotland, Britain.

Said, Edward. (1978). Orientaalism. London: London University Press.

Sterrett, Susan E. (2015). 'Interprofessional learning as a third space: Rethinking health profession students' development and identity through the concepts of Homi Bhabha' Humanities, 4: 653-660.

Wren, Thomas. (2002). 'Cultural identity and personal identity'. In Albert W. Musschengaet al. (eds.), Personal and Moral Identity, 231- 258.Detroit, Boston, London: Kluwer Academic Publishers. 